\title{
SCIENCE AND SUBPOENAS: WHEN DO THE COURTSBECOME INSTRUMENTS OF MANIPULATION?
}

\author{
PAUL M.FISCHER, M.D.* \\ 1

\section{INTRODUCTION}

O $n$ December 11, 1991, the Journal of the A merican Medical A ssociation (") A M A") published three studies that examined the effect of the Camel cigarette "O Id J oe" advertising campaign on adolescents and children. ${ }^{1}$ I was lead author on the study that showed that "O Id J oe" was nearly universally recognized by six-year-old children, a level of awareness that matched the logo for the Disney channel. Because cigarette smoking is the leading preventable cause of death and disease in this country, I recognized that this research might play a prominent role in the subsequent debate about tobacco advertising. A s a scientist, I naively assumed that this discourse would be conducted in academic journals based upon rigorous research and leading to an improved understanding of whether and how advertising influences adolescent experimentation with cigarettes. To date, most of the subsequent debate has occurred in court.

From the beginning, the tobacco industry attempted to discredit this research and harass the researchers. M y experience in confronting the tobacco industry has taught me how easily the courts can become the unwitting accomplices of an industry whose goal is profit, not the identification of scientific truth. In his paper in this issue of $L$ aw and Contemporary Problems, M ichael Traynor states that with "common sense and goodwill in every quarter" there should be few problems due to compelled discovery of scholarly research. ${ }^{2} \mathrm{U}$ nfortunately, in some cases, neither common sense nor goodwill prevail. In such cases, the court can become an instrument of abuse.

Copyright (C) 1996 by L aw and Contemporary Problems

*D octor of $\mathrm{F}$ amily M edicine, E vans, G eorgia.

1. Joseph R. Difranza et al., RJR Nabisco's Cartoon Camel Promotes Camel Cigarettes to Children, 266 J A M A 3149 (1991); Paul M. Fischer et al., B rand L ogo Recognition by Children A ged 3 to 6 Y ears: M ickey M ouse and Old J oe the Camel, 266 J A M A 3145 (1991); J ohn P. Pierce et al., D oes Tobacco A dvertising Target Y oung P eople to Start Smoking?, 266 J A M A 3154 (1991).

2. Michael Traynor, Countering the Excessive Subpoena for Scholarly Research, 59 LAW \& CONTEMP. PROBS. 119, 148 (Summer 1996). 


\section{A. A Chronology of Events}

The "OId J oe" studies were published in a J A M A theme issue dealing with tobacco research. ${ }^{3}$ The A merican $M$ edical A ssociation also held a press conference in $\mathrm{New} \mathrm{Y}$ ork to present the findings, ${ }^{4}$ which received wide coverage in the press. ${ }^{5}$

On M arch 9, 1992, The A merican Medical A ssociation, the Surgeon G eneral, the A merican Cancer Society, the A merican Heart A ssociation, and the A merican L ung A ssociation called for a ban on "Old J oe" advertising attractive to children. ${ }^{6}$ The following day, James J ohnson, C.E.O. of the R.J. R eynolds Tobacco Company ("RJR"), defended "Old Joe" in an interview published on the editorial page of U.S.A. Today. In this interview, he attacked the "Old Joe" studies and its researchers. ${ }^{8} \mathrm{Mr}$. Johnson argued that the "studies are flawed in very serious ways. The scientists who wrote these studies are not unbiased." ${ }^{9}$ He made two specific claims about our research that were not true. $\mathrm{H}$ e stated that the sample size was twenty three people ${ }^{10}$ when in reality it was 229 people. He also claimed that we called the parents of the three- to six-yearold children in our study the night before the data collection and asked them only about cigarette use. ${ }^{11}$ This statement was a total fabrication. Such a call to the parents would have obviously biased the results.

On M arch 27, I was served a subpoena duces tecum by RJR. ${ }^{12}$ A suit had been filed in California by Janet M angini against RJ R, based on RJ R 's failure to place health warnings on promotional products such as Camel caps and tshirts. ${ }^{13}$ I received the subpoena even though my research had not been named in the $M$ angini complaint, I was not a witness to either side in the case, and my 1991 J A M A research had no bearing on the issue of health warnings.

The subpoena ordered me to produce the following: the names and tele-

3. See supra note 1 .

4. See Stuart Elliott, Top Health O fficial Demands A bolition of "J oe Camel" A ds, N.Y. TIMES, Mar. 10, 1992, at A 1.

5. See, e.g., J ane E. Brody, Smoking A mong Children Is L inked to Cartoon Camel in A dvertisements, N.Y. TIMES, D ec. 11, 1991, at D 22.

6. Elliott, supra note 4.

7. R.J. Reynolds: A ds D o N ot Cause K ids to Smoke, U .S.A. TodA Y, M ar. 10, 1992, at 9A .

8. Seeid.

9. Id.

10. Seeid.

11. Seeid.

12. D efendant's N otice of $\mathrm{O}$ ut of State $\mathrm{D}$ eposition on $\mathrm{O}$ ral Examination and R equest for Production of Documents and Things, Mangini v. R.J. Reynolds Tobacco Co., N o. 939359 (Super. Ct., San Francisco Cty., Cal., M ar. 30, 1992).

13. See M angini v. R.J. Reynolds Tobacco Co., 21 Cal.R ptr.2d 232 (Cal. Ct. A pp.), rev. granted \& opinion superseded, 859 P.2d 672 (Cal. 1993), cert. denied, 875 P.2d 73 (Cal. 1994) (en banc), cert denied, 115 S. Ct. 577 (1994). 
phone numbers of all of the children who participated in the study; all drafts of the study design; all notes, memos, and videotapes pertaining to the study; the names, addresses, telephone numbers, background information, and occupations of all interviewers; hard copy tabulations and data tapes; originals of all test materials; all correspondence relating to the research; the names, addresses, and background information of all consultants; the names and addresses of all funding sources; and the names and telephone numbers of all respondents who were excluded from the study.

Given the published implications of my research, I had assumed that I might at some point be deposed about this study. I was, however, not prepared to receive a subpoena of this breadth and one that would require turning over the names of three- to six-year-old children. Such disclosure would have violated written confidentiality agreements that I had signed with each parent before conducting the research.

I had also anticipated that the Medical College of Georgia ("M CG"), on whose faculty I was a full professor and under whose auspices the research had been conducted, would provide appropriate legal support for my position. However, Michael Bowers, the A ttorney General of the State of Georgia and the official counsel for the medical school, took the position that the prevailing legal issue was not human subject confidentiality, academic freedom, or the reasonableness of the subpoena power, but rather the Georgia O pen R ecords A ct, a law designed to permit public access to "official records." ${ }^{14} \mathrm{M} \mathrm{r}$. Bowers took this position even though $\mathrm{RJ} R$ did not, at that time, request the records via the $O$ pen Records A ct. I refused to comply with the subpoena and MCG refused to provide me with legal assistance.

I contacted my own lawyer, R obert W. H unter, III, who prepared a motion to quash the RJR subpoena. ${ }^{15}$ On A pril 28, 1992, Chief Superior Court Judge William M. Fleming, J r., ruled in favor of our motion to quash. ${ }^{16} \mathrm{RJ} R$ immediately appealed the ruling to the Georgia Court of A ppeals, but that court, on February 9, 1993, ruled in our favor arguing that the requested documents were beyond the bounds of reasonable discovery. ${ }^{17}$

Two weeks later, in an article in a local newspaper, MCG lawyer Clay Stedman stated that the school had not supported my legal efforts because of their position on the $O$ pen R ecords A ct. ${ }^{18}$ Stedman said that M CG "decline[d] to object to [the] release of this information on the basis that although it was not an $O$ pen $R$ ecords [A ct] request, $O$ pen $R$ ecords would have required us to release it." ${ }^{19}$ Ironically, RJR attorneys did not know of M CG's position on this

14. O pen Records A ct, G A. COdE A NN. § 50-18-70 to -76 (Supp. 1996).

15. Motion to Quash, Fischer v R.J. Reynolds Tobacco Co., N o. 93-R CCV-230 (G a. Super. Ct. Richmond County, A pr. 16, 1992).

16. See Fischer v R.J. Reynolds Tobacco Co., No. 93-R CCV-230 (Ga. Super. Ct. Richmond County, A pr. 28, 1992) (order granting motion to quash).

17. See R .J. Reynolds Tobacco C o. v Fischer, 207 Ga. A pp. 292 (1993).

18. K athleen Donahue, Researcher Has Hefty L egal Fees, THE A U GUSTA CHRONICLE, Feb. 27, 1993, at 17A .

19. Id. 
issue and had previously admitted in their Court of A ppeals brief that they believed the records were not accessible to them under the $O$ pen $R$ ecords $A$ ct because the research had not been supported by state funds. ${ }^{20}$

O ne week after the publication of this article, James $R$. Johnson, legal counsel for RJR sent a letter to $H$. D ean Propst, Chancellor of the $U$ niversity System of G eorgia, and subsequently to Francis Tedesco, President of M CG, requesting that my research records be released to $R J R$ under the $O$ pen $R$ ecords A ct. ${ }^{21}$ I was given forty-eight hours to turn over all of the previously described records with the exception of the children's names. Clay Stedman, as MCG legal counsel, indicated that I would be suspended if I did not turn over the documents. Francis Tedesco, M.D., President of MCG, indicated that the A ttorney $\mathrm{G}$ eneral would have me arrested if I did not comply with the request.

A t the advice of my lawyer, I turned all of the documents over to the court for protection until such time as the legal issues relating to the $O$ pen $R$ ecords A ct, academic freedom, and human subject confidentiality could be resolved. The court accepted the documents and approved a temporary restraining order against the $O$ pen $R$ ecords request. ${ }^{22}$

O ne month later, RJR petitioned the court to assist M CG and the A ttorney General in the action against me. ${ }^{23}$ Both the A ttorney General's Office and MCG supported RJR's compelled disclosure motion. ${ }^{24}$ Ironically, this action united the medical school and a tobacco company against one of the school's own faculty members.

On A ugust 12, 1993, I received a nine-page letter listing documents and data requested by $R J R$ through the $O$ pen $R$ ecords $A$ ct. $^{25}$ It stated that $R J R$ wanted all documentation related to the study regardless of when it was generated or by whom. ${ }^{26}$ In response to a 1993 change in the O pen Records A ct which excluded release of the names of research participants, $R J R$ did request that the subject names be redacted from the submitted documents.

On D ecember 1, 1993, I resigned from the faculty of MCG and entered private practice in A ugusta. On July 20, 1994, Judge J ohn H. R uffin signed an $R J R$ request to release all of the records held by the court. The records were released to an $R J R$ lawyer before we were notified of the decision, making an appeal of this decision moot.

20. Petitioner's B rief, R.J. R eynolds T obacco v. Fischer, 207 G a. A pp. 292 (1993).

21. L etter from J ames R. Johnson, Legal Counsel, RJR, to Francis J. Tedesco, President, M C G (Mar. 10, 1993) (on file with author).

22. M otion for Temporary R estraining O rder, Fischer, No. 93-R CCV-230 (Ga. Super. Ct. Richmond County, M ar. 12, 1993).

23. See J ames R. J ohnson's M otion to I ntervene as a D efendant, Fischer, N o. 93-R CCV -230 (G a. Super. Ct. Richmond County, A pr. 22, 1993).

24. L etter from David M. M onde, A ttorney, J ones Day, R eavis \& Pogue, to Kathryn L. A llen, Senior A ssistant A ttorney G eneral (A pr. 20, 1993) (on file with author).

25. Letter from RJR to author (A ug. 12, 1993) (on file with author).

26. Seeid. 


\section{B. L essons L earned}

Every day in every academic institution, people request information from scientists. Most of the time this is done by fellow scientists in the process of scientific research. For example, after the publication of the "O Id J oe" study, I received requests from other researchers for specific information about our study and how it was done. Such requests are usually limited to information that would permit replication of the research. Successful replication is essential to establish scientific validity, and therefore scientists are usually pleased to share information.

Scientists do not use subpoenas to seek scientific truth! Thus, the subpoena of a researcher's files is evidence that the process has moved outside of the realm of scientific inquiry. As the cases cited in this paper illustrate, a subpoena usually means that the research in question has commercial implications and that a company has decided that its lawyers, rather than its scientists, are in the best position to protect the company's interests.

$\mathrm{N}$ evertheless, many subpoenas for research are routine. For example, a medical researcher might discover and report a series of side-effects in patients taking a new drug. The pharmaceutical company that manufactures the drug may then subpoena the records to see if there is an alternative explanation for the patients' symptoms. Other than concerns about patient confidentiality, such a subpoena would be handled in a routine fashion.

$\mathrm{H}$ owever, not all compelled disclosure is routine. In the extreme, subpoenas can be unwittingly used in a manner that is damaging to the researcher, the scientific process, and the greater public good.

III

\section{Dama Ging Effects of Extreme Subpoenas}

\section{A . D iscredit the R esearch. Discredit the R esearcher.}

It was clear from the U.S.A. Today interview that RJR wanted to discredit me and my research. ${ }^{27}$ Furthermore, this refutation would not follow the usual "rules" of science.

The standards for a published scientific paper require that the report include sufficient detail about the scientific methods utilized so that another individual in the field could duplicate the study. This was precisely what A dvertising A ge did after initially expressing reservations about the "O Id J oe" research. They commissioned research that was published five months later and showed that the Camel campaign was indeed highly effective in reaching young people, especially children younger than age thirteen. ${ }^{28}$ The president of the research company said, "I was blown away by the number of smaller kids who could

27. See R.J. R eynolds, supra note 6.

28. See G ary L evin, Poll: Camel A ds E ffective with Kids, A DVERTISING A GE, A pr. 27, 1992, at 12. 
name cigarettes." ${ }^{29} \mathrm{H}$ ad RJR been concerned about the veracity of our findings, they could have duplicated our research in several weeks for a few thousand dollars. Instead, they spent two and a half years, and a great deal more money, in an attempt to access every page in my files.

Why would RJR be interested in every scrap of paper in a research file? The answer to this question became clear from the experience of $D$ r. J oseph DiFranza, the lead author of one of the "Old J oe" studies. ${ }^{30} \mathrm{H}$ is research showed that $\mathrm{C}$ amel cigarettes' share of the youth market increased from a mere $0.5 \%$ to a substantial $32.8 \%$ following the "Old Joe" advertising campaign. ${ }^{31}$ D r. Difranza received a similar subpoena and turned over his records to RJR. In one of the letters to a colleague that was included in the disclosed documents, D r. D iFranza wrote, "I have an idea for a project that will give us a couple of smoking guns to bring to the national media." ${ }^{32}$ RJR released this letter to the press and claimed that it proved that the researchers were biased and that the research was fraudulent. ${ }^{33}$

It is easy to characterize any scientist as being biased. The public assumes that scientists enter into research without a point of view. Nothing could be further from the truth. Science is impossible to do without passion about an idea. Scientists are not without opinions, but they agree to subject these opinions to objective experiments to see if they are true. In every researcher's files, there are notes that could be taken out of context and characterized as proving bias.

In addition, every research study represents a series of methodological decisions about how data are collected and analyzed. These decisions require expert judgment and each of these judgments, when viewed in isolation, could be challenged. It is precisely because of this, that the final published paper becomes the record of the research. In the published manuscript, the researcher must describe the findings, discuss their meaning, and most importantly, identify the study's limitations.

The broad subpoena filed by R J R is akin to requiring a Supreme Court J ustice to report every private note made and every comment spoken in considering a case, rather than merely being responsible for the contents of the final opinion. It would be quite easy to discredit the decisions of even the best judges if their private notes and thoughts were publicly open on demand.

\section{B. H uman Subject Confidentiality}

The conduct of research on human subjects requires that the public have confidence that its best interests will be protected and that its confidentiality will be preserved. In the case of our research, $\mathrm{R} J \mathrm{R}$ requested the names and

29. Id.

30. DiFranza, supra note 1.

31. Seeid.

32. See M aria M allory, That's O ne A ngry Camel, Bus. W K., M ar. 7, 1994, at 94.

33. Seeid. 
addresses of 239 three- to six-year-old children whose parents had signed agreements in which we promised complete confidentiality. A ccording to Peggy Carter, an R J R spokesperson, the company intended to use this information to contact the research subjects. ${ }^{34} \mathrm{H}$ er reason for requesting this breach of confidentiality was that "[t]here have been a number of stories that have come up in recent years where scientists claimed to have produced research that ... was never done at all." ${ }^{35}$ While this reasoning is paranoid at best, it would not be necessary for RJR to knock on children's doors at night to prove that the data in question were collected, rather than fabricated.

The issue of subject confidentiality took an interesting legal turn in my case. MCG initially acknowledged the potential for abuse. In a letter from Carol Huston, one of the school's attorneys, to the A ttorney General's office, she stated that

[Fischer's] concern, which I believe is well founded, is that R eynolds is attempting to harass him (and other researchers) through tactics such as this in order to discourage future research, the results of which may not be favorable to the tobacco industry... . We also believe if [RJ R] obtains the names of the respondents, it seems very likely that [it] may contact them and attempt to harass them. This, in turn, may discourage other individuals from participating in future research projects.

D espite these observations by an M C G lawyer, the A ttorney General's position prevailed, and the school insisted that all names be released.

A s a general matter, institutions that participate in federally funded medical research must sign agreements with the Department of Health and Human Services ("DHHS"), by which they agree to conduct research according to federally-established guidelines. Human subject confidentiality is well-protected by these standards. My study, however, was not federally funded and was subject to these guidelines only because of contractual agreements between D H HS and MCG.

On September 8, 1992, I was contacted by the acting chief of the Office of Protection from R esearch R isks of the $\mathrm{N}$ ational Institutes of $\mathrm{H}$ ealth. He had heard of my case and wanted information about any breach of human subject protection. He subsequently sent a letter to the school alleging noncompliance with their DHHS contract because of the school's position requiring release of my subjects' names. The school responded that the federal regulations could be avoided because my research was not federally funded. DHHS and MCG subsequently signed a revised contract in which only federally funded research was governed by federal regulations regarding subject confidentiality.

\section{H arassment}

The tobacco industry approach to litigation has been described by Lawton M. Chiles, Jr., Governor of the State of Florida, as "designed to confuse the medical evidence, stone-wall, delay, refuse reasonably to settle claims, and to

34. See Marcia Barinaga, Who Controls a Researcher's Files? Tobacco Company R.J. Reynolds Subpoenas Research Study D ata, 1256 SCI. 1620 (1992).

35. Id. 
run up plaintiffs' attorneys' fees in a war of attrition." ${ }^{36}$ He cites a memo written by J. M ichael J ordan, an attorney for R J R :

The aggressive posture we have taken regarding depositions and discovery in general continues to make these cases extremely burdensome and expensive for plaintiffs' lawyers, particularly sole practitioners. To paraphrase General Patton, the way we won these cases was not by spending all of R eynolds' money, but by making the other son of a bitch spend all his. ${ }^{37}$

This same approach was used to wear down my resources, including my time, attention, and money. The ultimate goal is to make the process sufficiently painful so that the researcher cannot complete further research and so that other scientists are discouraged from conducting similar studies.

Scientists are perfect subjects for harassment by litigation. They often have little knowledge of the law and little patience for the slow and subtle workings of the legal system. The distraction and anxiety caused by depositions, legal costs, and court appearances can easily put an abrupt end to a promising line of research or a research career.

It should be noted that R J R did not limit its harassment efforts to the use of the press and the courts. It also attempted to conscript the institution at which I worked. Bernard Wagner, M.D., Professor at the New York U niversity School of Medicine and paid consultant to RJR, contacted my research colleagues and the President of MCG with accusations of scientific fraud. ${ }^{38} \mathrm{~A}$ similar letter was sent to the $U$ niversity of $M$ assachusetts regarding $D r$. D iFranza's "Old J oe" study. ${ }^{39}$ While MCG did not respond, the U niversity of $M$ assachusetts used these baseless accusations to initiate scientific misconduct hearings against Dr. DiFranza. He was eventually found innocent of these charges. $^{40}$

\section{IV}

\section{SUGGESTIONS}

A s a researcher who has been through the experience of compelled disclosure, many of the suggestions outlined in this paper do not appear to be viable solutions to the problem that I faced. I would not argue that scientists deserve special protection under the law in the same way that lawyers, priests, or journalists have claimed the need for protection of their relationships with clients, parishioners, and confidential sources. Science, after all, is based on a shared and open search for truth. I am not, however, so naive as to believe that most subpoenas for research records are based on goodwill, public interests, or the search for truth. I offer the following thoughts:

36. Complaint, Florida v. A merican Tobacco Co. et al., No. CL-1466A 0 (Circuit Ct.,15th Circuit, Palm B each. Fla., A pr. 18, 1995)

37. Id. at 28-29 (memorandum from J . M ichael J ordan, legal counsel, R J R).

38. Letter from B ernard Wagner to Tina R ojar ( $M$ ar. 29, 1993) (on file with author).

39. Based on the author's conversations with D r. D iF ranza.

40. Id. 
First, if a request for compelled disclosure has been made, realize that the process has moved outside of the normal exchange between scientists. It is likely that a commercial entity and its profits are at stake. It is also likely that the company will have greater legal resources and experience than the scientist, who may have never stepped foot inside a courtroom.

Second, despite institutional affiliation and responsibilities to protect academic freedom, universities may provide poor legal counseling to scientists facing compelled disclosure. This problem may become greater due to the increased reliance of universities on corporate support. We might expect to see university presidents siding with corporate contributors rather than their academic faculty.

N ext, if a subpoena is requested by an industry, consider the industry's past record in dealing with the scientific community. Consider whether the industry has used the legal system to discourage good science in the past.

A Iso, consider the breadth of the request. If it goes far beyond what a reasonable scientist would require to duplicate the research, then there may be other ways that the company could validate the research findings without violating the privacy of the scientist's records.

A sk the scientist to identify specifically how compelled discovery could impede his research. It is impossible for the court to balance the rights of the company with those of the scientist unless it understands the implications of the legal process on the scientist's time, attention, and financial resources.

Finally, human subject confidentiality, promised as part of the research process, must be protected at all costs. There are excellent ways to identify scientific fraud without violating anonymity, such as the use of an independent review panel of scientists.

$\mathrm{V}$

\section{CONCLUSION}

The uneasy relationship between law and science is likely to continue regarding disclosure of scientific research materials. Law and science are worlds apart in terms of values that they hold and the rules that they follow. Whether it be DNA evidence or silicone breast implants, it appears that these two worlds will collide with ever-increasing frequency. This inevitable collision will require that scientists have a better understanding of the legal implications of their research and that judges have a better understanding of the impact of their decisions on the progress of science. 